\title{
HISTÓRIA DA EDUCAÇÃO E MEMÓRIAS DE PROFESSORES ${ }^{1}$
}

\author{
Thiago Rodrigues Nascimento ${ }^{2}$ \\ (FFP/UERJ/FAPERJ)
}

\begin{abstract}
RESUMO
O presente texto foi produzido a partir das muitas questões que surgem na relação entre história da educação e História. A vivência em um Programa de Pós-Graduação em História Social levantou indagações como: Qual seria nosso lugar, enquanto pesquisadores da história da educação? Estaríamos vinculados à História ou à Educação? Quais seriam nossos referenciais teóricos? Traçamos, a partir destes questionamentos, um breve histórico do processo de constituição da história da educação e da pesquisa produzida neste campo demonstrando que, apesar da persistência de certo distanciamento entre esta disciplina e a História, nos últimos anos, a partir de um processo de ampliação do "território" do historiador, a Educação tornou-se objeto da História. Processo que vem contribuindo para a diminuição das barreiras de um campo que busca a sua consolidação. Compreendendo a Educação como objeto da História, apresentamos a história oral e suas possibilidades e os usos das memórias de professores enquanto fonte para o estudo da história da educação brasileira. Assim, deslocamos o enfoque, ainda tradicional entre os pesquisadores, concedido às fontes escritas.

Palavras-chave: História da educação; História Oral; Memórias de professores.
\end{abstract}

\section{EDUCATION OF HISTORY AND MEMORIES OF TEACHERS}

\begin{abstract}
This text was produced from the many questions that arise in the relationship between history of education and history. Living in a Post-Graduate Program in Social History raised questions as: What is our place, as researchers in the history of education? We would be linked to history or education? What are our theoretical? We draw from these questions, a brief history of the process of establishing the history of education and research in this field produced showing that, despite the persistence of some distance between this discipline and history, in recent years, from a process of expansion the "territory" of the historian, Education became the object of history. Process that has contributed to the decrease of barriers to a field that seeks to consolidate. Understanding the History of Education as an object, we present the oral history and its possibilities and uses of memories of teachers as a resource for the study of the history of Brazilian education. Thus, we shift the focus, even among traditional researchers, given to written sources.
\end{abstract}

Keywords: Education of History; Oral History; Memories of Teachers. 
[...] a História é antes de mais nada a busca incessante, porque histórica, de um objeto que é, essencialmente movimento [...] apreendida de maneiras diferentes, é rescrita por cada geração, é interpretada desde muitos pontos de vista (FENELON, 1984, p. 22).

O impulso para a confecção do presente texto surgiu nos primeiros dias como discente no Programa de Pós-graduação em História Social da Universidade do Estado do Rio de Janeiro (PPGHS/UERJ). A primeira rodada de apresentação dos projetos dos novos alunos demonstrou a variedade de temáticas e objetos de estudo: Farmacopeia Lusitana, homens de negócio no Brasil e Portugal setecentista, abolicionismo em Vassouras/RJ, questão agrária no governo João Goulart (1961 - 1964), apenas citando alguns. Trabalhos de História, sem discussão. Somados a estes mais três projetos foram apresentados: o nosso sobre a trajetória da licenciatura curta em estudos sociais, na Faculdade de Formação de Professores de São Gonçalo/RJ, durante os anos $1970-1980^{3}$ e outros trabalhos que versavam sobre a história da educação profissional em Rio Bonito $(\mathrm{RJ})$ e a inserção das mulheres no magistério durante a Primeira República. Qual seria nosso lugar, enquanto pesquisadores da história da educação? Estaríamos vinculados à História ou à Educação? Quais seriam nossos referenciais teóricos?

Eliane Marta Teixeira Lopes parece, de um lado, responder parte dessas indagações, e por outro apresenta uma discussão que vem sendo debatida ao longo dos últimos anos - o lugar da história da educação no "território" do historiador.

Um trabalho de História da Educação não consegue deixar de ser um trabalho de história, "mesmo por que não há história da política, do direito, da ciência etc., da arte, da religião etc." (...) O que há é história. No entanto, faz-se história da educação e escreve-se história da educação: história das idéias e correntes pedagógicas, história da escola ou das instituições escolares, história da educação popular etc. (LOPES apud CATANI e FARIA FILHO, 2002, p. 113).

Lopes (1985) adverte que o que há é a História, porém existem diferentes escritas desta História com suas muitas possibilidades e uma delas é a história da educação. Francisco Falcon (2006), no artigo História cultural e história da educação, destaca algumas obras que, produzidas a partir dos anos setenta, analisam, sob diferentes perspectivas, os rumos da produção historiográfica mundial. O autor argumenta que "se pode observar nesse universo textual a ausência quase completa de trabalhos relativos à história da educação, como se não competisse realmente aos historiadores o estudo e a pesquisa de tal história" (p. 328). Exemplificando, o historiador cita obras como a trilogia História: novos objetos, História: novas abordagens e História: novos problemas, organizada por Jacques Le Goff e Pierre Nora (1976) e a obra Domínios da História, publicada em 1997 e organizada pelos historiadores fluminenses Ciro Flamarion Cardoso e Ronaldo Vainfas. Não há, nestes trabalhos, referências à história da educação.

Obras recentes publicadas a partir dos anos 2000, como grandes coletâneas sobre a história brasileira ou contemporânea, também não apresentam capítulos dedicados à história da educação. Podemos citar coleções como O Brasil Republicano (2003), organizada em quatro volumes por Jorge Ferreira e Lucilia Delgado e $O$ século XX (2000), organizado em três volumes por Celeste Zenha, Daniel Aarão Reis Filho e Jorge Ferreira. Em 2004, na esteira dos 40 anos do golpe civil-militar que derrubou o governo Jango (1961 - 1964), inúmeros seminários, debates e outros tipos de encontros foram realizados 
no país, originando livros como $O$ golpe e a ditadura militar: 40 anos depois (1964 2004), organizado por Daniel Aarão Reis, Marcelo Ridenti e Rodrigo Motta (2004). Entretanto, apesar das transformações implementadas pelos militares na educação brasileira, como a Reforma do Ensino Superior de 1968 e a Reforma de Ensino de $1^{\circ}$ e $2^{\circ}$ graus de 1971, os organizadores, desta coletânea, não dedicam uma parte do livro à história da educação durante o regime que durou mais de duas décadas ${ }^{4}$.

Há também, as obras que abordam ou discutem "os problemas principais das relações entre a história da educação e a história produzida pelos historiadores" (FALCON, 2006, p. 330), bem como questões metodológicas e temas próprios da história da educação ${ }^{5}$. Contudo, estas produções parecem trilhar caminhos distintos, História e história da educação em lugares opostos. Thaís Nivia de Lima e Fonseca (2003) salienta que,

um olhar mais cuidadoso sobre alguns textos de natureza analítica, que tratam de questões teórico-metodológicas, demonstra embaraços na definição das relações entre Nova História, a História das Mentalidades, a História Cultural, a História Social e seus entrelaçamentos com outras "histórias", como a política, a econômica, das idéias, do cotidiano, entre outras. A imprecisão é grande quando se trata de apontar cada uma como proposta metodológica, tendência, vertente, corrente ou campo.

A historiadora argumenta que,

mais problemático ainda é constatar que a História da Educação, não é considerada como nenhum deles, a não ser em textos escritos por pesquisadores diretamente nela envolvidos, mas não no conjunto da produção historiográfica (FONSECA, 2003, p. 50).

No Brasil, a pesquisa em história da educação teve um maior desenvolvimento no terreno da Educação, o que, inicialmente, explicaria este distanciamento explicitado nas linhas anteriores entre a produção historiográfica e a escrita da história da educação. De acordo com Arlette Gasparello (2007, p. 75), em nosso país "a pesquisa em história da educação desenvolveu-se inicialmente no interior de um grupo ligado a esta disciplina escolar no curso de formação de professores". Nos últimos anos, a partir de um processo de ampliação do "território" do historiador, a Educação tornou-se objeto da História e a história da educação, torna-se, a cada dia, um campo possível para os historiadores, o que contribui para a diminuição das barreiras de um campo que busca o seu espaço. Entretanto, longos anos de distanciamento entre historiadores e história da educação não desaparecem de uma hora para outra. É um trabalho contínuo.

Um estudo sobre a configuração e a trajetória da pesquisa em história da educação no Brasil requereria um trabalho que vai muito além dos limites deste texto, o que torna necessário um processo de seleção. Margarida Louro Felgueiras (1994, p. 29) adverte que "todas as correntes [históricas] atuais salientam o papel ativo do historiador na seleção e análise do material de estudo, na pesquisa em função dos problemas do presente em que o historiador está inserido". Assim, a partir do problema que delineamos nos parágrafos anteriores, o presente artigo, aborda algumas questões que tem embalado as discussões em torno da consolidação da pesquisa em história da educação e algumas temáticas que vêm sendo desenvolvidas no âmbito da pesquisa, com destaque para as transformações que têm sido operadas neste campo de análise a partir da última década do século XX. Para tanto, tomamos como referência textos de historiadores e educadores que vêm pensando as 
relações entre história da educação e historiografia e, ainda, trabalhos que buscam discutir os aspectos teórico-metodológicos da história da educação.

$\mathrm{O}$ artigo foi dividido em duas partes principais. Na primeira, traçamos um breve histórico da história da educação e da pesquisa neste campo. Num segundo momento, discutimos a história oral e suas possibilidades na pesquisa em história da educação e os usos da memória de professores enquanto fonte para o estudo desta no Brasil, destacando as fontes escritas, para além das consideradas oficiais, os documentos escritos, como os compêndios ou as legislações educacionais. Apresentamos aspectos da pesquisa que vem sendo desenvolvida no âmbito do mestrado em História Social da UERJ.

\section{Apontamentos sobre a pesquisa em História da Educação}

A história é busca, portanto escolha. Seu objeto não é o passado: "A própria noção segundo a qual o passado enquanto tal possa ser objeto de ciência é absurdo". Seu objeto é "o homem", ou melhor, "os homens", e mais precisamente "homens no tempo" (LE GOFF, 2001, p. 24) ${ }^{6}$.

Ninguém escapa da educação. Em casa, na rua, na igreja ou na escola, de um modo ou de muitos todos nós envolvemos pedaços da vida com ela: para aprender, para ensinar, para aprender-e-ensinar. Para saber, para fazer, para ser ou conviver, todos os dias misturamos a vida com a educação (BRANDÃO, 1995, p. 7).

A História é a "ciência dos homens no tempo", estudo do homem e das suas relações. "Os homens se parecem mais com sua época do que com seus pais", adverte um provérbio árabe. Neste percurso, é lícito afirmar que "ninguém escapa da educação". Ela se processa em todos os lugares, na escola e fora dela, uma forma de interagir dos homens em diferentes tempos, uma forma de ver o indivíduo em relação à história de seu tempo. Concordamos, assim, com Cynthia Veiga e Thaís Fonseca (2003, p. 8), quando argumentam que se não escapamos da educação, também não escapamos de uma história da educação. Neste sentido,

(...) uma constatação evidente é a de que investigar os processos do aprender é fundamental para ampliarmos a compreensão das formas de como em tempos e espaços distintos, homens e mulheres organizaram sua vida, seus afazeres e suas idéias, enfim, seu modo de ser e estar no mundo (Idem, p. 8).

Através desta perspectiva a história da educação é importante para compreendermos as formas como os homens organizam suas vidas e relações com o grupo em que estão inseridos. Mas como esta história tem sido escrita no Brasil? E em que sentido, os trabalhos escritos por professores e pesquisadores nos últimos anos vêm contribuindo para a ampliação do debate sobre a escrita da história da educação, sua história e suas relações com as diferentes possibilidades de abordagem do campo? A história da educação, enquanto disciplina, foi introduzida nos cursos de formação de professores a partir da segunda metade do século XIX. De acordo com Maria Isabel Nascimento e Manoel Nascimento (2010, p. 186 e 187), o seu objetivo era "compreender os princípios, as experiências, os sucessos e as decepções dos educadores do passado", como "antídoto para não se repetir no presente, os erros do passado". Uma perspectiva de história como mestra da vida, múltiplas experiências alheias apropriadas com objetivos pedagógicos (KOSELLECK, 2006, p. 42). 
Gasparello (2007) esclarece que a pesquisa em história da educação no Brasil teve início com os professores que ministravam estas disciplinas nos cursos normais. Pessoas formadas nas mais diferentes áreas do conhecimento. Diana Vidal e Luciano Mendes de Faria Filho (2003), no artigo História da Educação no Brasil: a constituição histórica do campo (1880-1970) elaboram um histórico da disciplina a partir de três vertentes: a tradição historiográfica do Instituto Histórico e Geográfico Brasileiro (IHGB), a história da educação e as escolas normais e a produção acadêmica difundida entre os anos 1940 e 1970. De acordo com os autores, o primeiro livro voltado, exclusivamente, para narrar a história da educação brasileira foi escrito em francês, pelo médico Ricardo Pires de Almeida nos anos finais do Império - L'Instruction publique au Brésil: historie e legislation (1500-1889). Apresentando estatísticas, tinha como um de seus objetivos "afirmar a liderança brasileira em termos educacionais" (VIDAL E FARIA FILHO, 2003, p. 40).

Segundo Vidal e Faria Filho (2003, p. 41), o livro de Pires de Almeida respeitava uma postura positivista de escrita da história. As produções analisadas pelos autores, até aproximadamente os anos 1960, apresentavam como suas principais propostas coligir e metodizar documentos e buscavam "interpretar a gênese da civilização brasileira, ambas caras à tradição narrativa da história gestada pelo IHGB” (idem, 2003, p. 42). Um exemplo destes trabalhos é a coleção de Primitivo Moacyr, publicada entre 1936 e 1942 em 15 volumes ${ }^{7}$, onde o advogado e ex-funcionário da Câmara dos Deputados realizou um "levantamento e compilação de leis, estatutos e regimentos escolares, memórias, relatórios e pareceres sobre instrução pública e particular nos vários ramos do ensino (primário, secundário, profissional e superior) no Brasil". Um processo de investimento, sistematização e divulgação de documentos e fontes para a história da educação que prosseguiria durante os anos 1960 (VIDAL e FARIA FILHO, 2003, p. 43 - 44).

Em 1928, foi introduzida, através da reforma da instrução pública do Distrito Federal realizada por Fernando de Azevedo a partir de 1927, a disciplina história da educação no currículo da Escola Normal do Rio de Janeiro. Um dos primeiros a lecionar a disciplina foi o médico e membro da Academia Brasileira de Letras Júlio Afrânio de Peixoto, autor do primeiro manual didático brasileiro sobre história da educação publicado em 1933. Segundo Vidal e Faria Filho (2003, p. 47 - 49), este autor inaugura uma espécie de regra narrativa que iria se colocar como exemplo de escrita para outros manuais produzidos nos anos seguintes, estabelecendo um modelo de pesquisa centrado na compilação de leis e estatísticas. Quando analisam a terceira vertente de constituição do campo, a história da educação e a escrita acadêmica entre os anos 1940 e 1970, os autores destacam o livro Cultura Brasileira de Fernando de Azevedo, publicado em 1943, e o grupo de pesquisadores oriundos de diferentes departamentos da Universidade de São Paulo (USP) e de outras instituições deste estado. A partir da fonte primária, cada pesquisador deste grupo investigou temas ou personagens do passado educacional brasileiro, enfocando os séculos XVIII ao $\mathrm{XX}^{8}$ (VIDAL e FARIA FILHO, 2003, p. 52 $55)$.

Apresentamos, brevemente, a periodização estabelecida por Vidal e Faria Filho (2003) para a constituição do campo da história da educação no Brasil. Os autores traçam um perfil desta disciplina e de suas principais produções ao longo de noventa anos destacando os principais autores e filiações e o surgimento de formas de pesquisa em história da educação, inicialmente, ligadas a tradição historiográfica do IHGB e que, posteriormente, se aproximaram da área da Educação e da Filosofia da Educação.

Uma produção científica que não nasceu nas universidades. A partir de meados dos anos 1960 e inícios dos anos 1970, com o surgimento dos programas de Pós-Graduação em 
Educação no país, os primeiros na Pontifícia Universidade Católica do Rio de Janeiro em 1965 e na Pontifícia Universidade Católica de São Paulo em 1969, e dos anos 1980, com a constituição de associações e grupos científicos da área - o Grupo de Trabalho História da Educação da Associação de Pós-Graduação e Pesquisa em Educação (1984), o Grupo de Estudos e Pesquisas "História, Sociedade e Educação no Brasil" (HISTEDBR) em 1986 e a Associação Sul-Rio-Grandense de Pesquisadores em História da Educação criada em $1996^{9}$-, a produção e divulgação de trabalhos em história da educação cresceu consideravelmente (VIDAL e FARIA FILHO, 2003, p. 37). Este crescimento das pesquisas tem sido atestado em artigos como o de Denise Barbara Catani e Luciano Mendes de Faria Filho (2002), sobre os trabalhos apresentados no GT História da Educação da ANPEd entre 1985 e 2000.

Se, o campo da história da educação se constituiu através de trabalhos de grandes intelectuais formados nas mais diferentes áreas do conhecimento, nos últimos anos têm ocorrido o que Clarice Nunes qualifica como
uma mudança de atitude: já não nos envergonhamos mais de fazer história, apesar de, em geral, não termos formação em cursos de graduação ou pós-graduação em História. Abraçamos com maior clareza as lutas da história da educação dentro da História (processo/disciplina). Sejamos historiadores ou pedagogos por formação, somos historiadores pelo projeto e pela prática de trabalho [grifo nosso] (Apud CATANI e FARIA FILHO, 2002, p. 118 - 119).

Ocorre, a partir dos anos 1980, uma maior aproximação entre História e história da educação, seja pela "prática de trabalho", como argumenta Nunes, seja pela maior inserção de historiadores graduados ou pós-graduados em História neste campo de pesquisa ${ }^{10}$. Segundo Marta Chagas de Carvalho, Dermeval Saviani e Diana Vidal (2008), neste período,

começa a ganhar visibilidade um movimento de discussão e revisão historiográfica que põe em questão os padrões então dominantes na produção sobre História da Educação brasileira. Há indícios de que esse movimento está em curso desde a segunda metade dos anos 70 como tendência, que vai se avolumar e se adensar dez anos depois.

Um movimento de revisão crítica, debates, discussão de questões teóricometodológicas e de contestação dos padrões dominantes da pesquisa em história da educação produzida até então (Marta Chagas de Carvalho; Dermeval Saviani e Diana Vidal, 2008). Novas questões, novas fontes, novos temas, novas categorias de análise passam a ser considerados e discutidos nos diferentes GT(s) e encontros. Velhos objetos são revistos. Um percurso de mudanças que ainda precisa ser mais bem analisado e que não se restringe à pesquisa em história da educação. Uma questão nos interessa em particular, o lugar da pesquisa em história da educação. Autores como Mirian Warde (1990), Francisco Falcon (2006) e Arlette Gasparello (2007), argumentam que a história da educação configurou-se afastada do campo de investigação da história, não como uma especialização temática da história, mas como uma "ciência da educação" ou como "ciência auxiliar da educação". Certamente, este aspecto ajuda a explicar o desenvolvimento das pesquisas em educação e história da educação majoritariamente no âmbito dos Programas de Pós-Graduação em Educação ${ }^{11}$.

Vidal e Faria Filho (2003, p. 60), defendem que a história da educação é ao mesmo tempo "uma subárea da Educação e uma especialização da História". O pertencimento da 
história da educação como especialidade da História e como uma subárea da Educação, parece ser uma saída para esta discussão, uma vez que a Educação pode ser tanto um objeto de pesquisa do historiador quanto do "educador/historiador" (GASPARELLO, 2007, p. 75). Neste sentido,

Para os historiadores da educação isto tem significado uma forma de marcar o seu pertencimento à comunidade dos historiadores, e uma maneira de reafirmar a identificação de suas pesquisas com os procedimentos próprios do fazer historiográfico [...] (VIDAL e FARIA FILHO, 2003, p. 60).

Nascimento e Nascimento (2010) argumentam que a História tem produzido diferentes concepções e métodos, "assim como há diversas compreensões sobre o papel do historiador na atividade de fazer história". Da mesma forma, na pesquisa em história da educação têm sido adotadas inúmeras formas de se analisar o objeto histórico. Segundo estes autores, "as principais concepções de história que influenciam [ou influenciaram] a produção na área são identificadas como: positivista; marxista; do Grupo dos Annales e da História Nova" (NASCIMENTO e NASCIMENTO, 2010, p. 187). Acrescentaríamos a este conjunto, as recentes contribuições teórico-metodológicas da História Cultural para o campo $^{12}$. Fonseca $(2003$, p. 61) argumenta que é "inegável uma mudança no perfil da pesquisa em História da Educação no Brasil e a influência que a História da Cultural tem tido nela".

Assim, velhos objetos têm sofrido releituras a partir dos referências da História Cultural e novos objetos são destacados. Segundo Fonseca (2003, p. 61), "predominam [nas pesquisas atuais] a história da leitura e dos impressos, sobretudo os escolares, a história da profissão docente, os processos de escolarização, a cultura escolar e as práticas educativas e pedagógicas". Entretanto, mesmo com novos objetos, prevalece ainda, na pesquisa em história da educação, a fonte escrita (NASCIMENTO e NASCIMENTO, 2010; FONSECA, 2003). Neste trabalho, apresentamos uma proposta de pesquisa sobre a história da educação brasileira utilizando como fonte a História Oral e as memórias de professores.

\section{História Oral e história da educação: breves considerações ${ }^{13}$}

As primeiras experiências no campo da História Oral no Brasil datam de 1975. Neste ano cursos foram ministrados, por pesquisadores mexicanos e norte-americanos patrocinados pela Fundação Ford, na Fundação Getúlio Vargas (FGV) - Rio de Janeiro, tendo como público professores da área de Ciências Humanas oriundos de diferentes instituições do país. Desta forma, "a introdução da História Oral no Brasil ocorreu essencialmente através dos meios acadêmicos, dos centros de pesquisa e das universidades" (FERREIRA, 1998, p. 19 e 23).

Ao longo das últimas décadas, sobretudo, a partir da década de 1980, a História Oral tem se tornado fonte e ferramenta importante para os historiadores que se dedicam a analisar processos históricos recentes ou buscam, nas palavras de Lucilia Delgado (2006, p. 15), "recuperar informações sobre acontecimentos e processos que não se encontram registrados em outros tipos de documentos [...]". Desta forma, a História Oral descortina uma série de processos antes ignorados, permitindo aos historiadores o acesso a diferentes testemunhos e tornando possível novas interpretações do passado. Paul Thompson (1992, p. 26-27 e 44) defende que a História Oral contribui para uma mudança de enfoque e para a 
abertura de novas áreas importantes de investigação, ampliando e enriquecendo o campo de ação da produção histórica. Uma história construída em torno de pessoas.

Consideramos a definição de História Oral formulada por Delgado (2006, p. 15), como “[...] um procedimento metodológico que busca, pela construção de fontes e documentos, registrar, através de narrativas induzidas e estimuladas, testemunhos, versões e interpretações sobre a História em suas múltiplas dimensões". No campo da história da educação, a História Oral nos coloca em contato com as experiências e memórias de professores e alunos, rompendo com a barreira que antes limitava as pesquisas à análise das políticas públicas e as escolas pedagógicas. Segundo Emery Marques Gusmão (2004, p. 31), "a História Oral, aplicada [à história da educação], pode iluminar lugares ocultos da vida escolar, apontar formas sutis de resistência e sublinhar os efeitos de currículos, normas e diretrizes".

Assim, utilizamos como percurso metodológico a História Oral temática, "pela necessidade e possibilidade de ouvir os sujeitos envolvidos no processo educacional, captar as suas experiências [...] e abrir um campo para possíveis análises" (MESQUITA e FONSECA, 2006, p. 334). A partir do tema (licenciatura curta em estudos sociais e sua trajetória), problemas e objetivos esboçados, a investigação está sendo desenvolvida por meio de entrevistas temáticas, ou seja, "entrevistas que se referem às experiências ou processos específicos vividos ou testemunhados pelos entrevistados" (Delgado, 2006, p. 22). Entendemos a metodologia da história oral como ferramenta de produção de conhecimento, onde se privilegia a interação entrevistador e entrevistado. Desta forma, "entrevista é fonte criada pela interação entre entrevistado e entrevistador. Este deve ajudar o entrevistado a "ativar" suas lembranças e a estruturar sua narrativa de modo que tenha fluidez" (CIAMPI, 2008, p. 214). Partimos do pressuposto de que memória, "atualiza o tempo passado, tornando-o tempo vivo e pleno de significados no tempo presente" (DELGADO, 2006, p. 38).

\section{As memórias de professores como fonte para a História da Educação Brasileira}

Nas últimas décadas, a história se aproximou da memória e aprendeu a interrogá-la; a expansão das 'histórias orais' e das micro-histórias é suficiente para provar que este tipo de testemunho obteve uma acolhida tanto acadêmica como midiática (SARLO, 2007, p. 43).

Beatriz Sarlo (2003) adverte, no livro Tempo Passado: cultura da memória e guinada subjetiva, que o passado é sempre conflituoso e que a este se referem, quase sempre em concorrência, a memória e a história. Uma desconfiança mútua regeria as relações entre história e memória. Fernando Catroga (2001, p. 44) argumenta que "parece excessivo defender tanto a existência de uma diferença radical, como uma semelhança entre a memória e a história". Segundo o autor,

Se é verdade que a história vivida se distingue da história escrita (M. Halbwachs), o certo é que outras características, apresentadas como típicas da memória (seleção, finalismo, presentismo, verossimilhança, representação), também se encontram no trabalho historiográfico, dado que, hoje, este não se cinge à busca de explicações por causalidade eficiente, e a visão linear, acumulativa, homogênea e universalista do próprio progresso dos conhecimentos sobre o passado é contestada (CATROGA, 2001, p. 40). 
Se, por um lado, compreendemos as diferenças entre memória e história, isto é, a "especificidade de ambas as narrações sobre o passado", por outro, não podemos negar o estudo da memória como um dos meios de se abordar os problemas do tempo e da história (LE GOFF, 2003, p. 422). A memória como matéria-prima da história (LE GOFF, 2006, p. 17). A memória, no seu sentido mais largo é a presença do passado. Uma construção psíquica e intelectual que acarreta uma representação seletiva do passado, um passado que nunca é do indivíduo somente, mas do sujeito inserido em diferentes contextos: nacional, social, familiar (ROUSSO, 2002, p. 94). Nas palavras de Henry Rousso (2002, p. 94 - 95), "seu atributo mais imediato é garantir a continuidade do tempo e permitir resistir à alteridade, ao 'tempo que muda', as rupturas que são o destino de toda vida humana; em suma, ela constitui (...) um elemento essencial da identidade, da percepção de si e dos outros". Assim, de acordo com Catroga:

[a memória] não é um armazém que, por conseguinte, recolha todos os acontecimentos vividos por cada indivíduo, um mero registro; mas é retenção afetiva e "quente" do passado feita dentro da tensão tridimensional do tempo (2001, p. 20).

Catroga (2001, p. 26) adverte ainda sobre a impossibilidade de se recordar a totalidade do que passou e a recordação e sua "função" de distinção e diferenciação de um indivíduo em relação ao outro, a partir da inserção dos indivíduos em cadeias de filiação identitária. Na perspectiva de Maurice Halbwachs (2006), toda memória é coletiva. Para este autor,

[...] cada memória individual é um ponto de vista sobre a memória coletiva, e este ponto de vista muda conforme o lugar que ali ocupo, e que este lugar mesmo muda segundo as relações que mantenho com outros meios... A sucessão de lembranças, mesmo daquelas que são mais pessoais, explica-se sempre pelas mudanças que se produzem em nossas relações com os diversos meios coletivos, isto é, em definitivo, pelas transformações desses meios, cada um tomado à parte e em seu conjunto (HALBWACHS, 2006, p. 51 Apud FONSECA, 2006, p. 34)

Michael Pollak (1992) argumenta que, a priori, a memória parece ser um fenômeno individual, íntimo e próprio da pessoa. Mas o próprio sociólogo retoma Halbwachs e argumenta que este último já nos anos 1920-1930, "havia sublinhado que a memória deve ser entendida também, ou, sobretudo, como um fenômeno coletivo ou social, ou seja, como um fenômeno construído coletivamente e submetido a flutuações, transformações, mudanças constantes" (POLLAK, 1992, p. 201). Neste aspecto as concepções de memória adotadas por Pollak (1992) e Rousso (2002) se assemelham, na medida em que para o segundo a memória também é considerada uma construção coletiva, no sentido de que o indivíduo não está isolado no mundo.

Rousso (2002, p. 95) estabelece uma distinção entre o "caráter coletivo da memória" e "memória coletiva". Segundo o autor, o caráter coletivo de toda memória individual é evidente, isto é, a memória, como "representação seletiva do passado", é construída em termos individuais por um sujeito que está inserido em um contexto maior. Por outro lado, utiliza o conceito de memória coletiva para designar "as representações do passado observadas em determinada época e em determinado lugar" por indivíduos de uma mesma comunidade. Compreende que memória coletiva é uma representação do passado 
compartilhada nos mesmos termos por toda uma coletividade. Catroga (2001, p. 16) argumenta que "a memória individual é formada pela coexistência, tensional e nem sempre pacífica, de várias memórias (pessoais, familiares, grupais, regionais, nacionais, etc.)". Ainda, segundo este autor,

a formação do eu de cada indivíduo [e, consequentemente, a "construção" de sua memória] será, assim, inseparável da maneira como ele se relaciona com os valores da(s) sociedade(s) e grupo(s) em que se situa e do modo, como à luz do seu passado, organiza o seu percurso como projeto (Catroga, 2001, p. 20).

Neste sentido, seguindo a argumentação de Pollak (1992, p. 204),

(...) a memória é um fenômeno construído. Quando falo em construção, em nível individual, quero dizer que os modos de construção podem tanto ser conscientes como inconscientes. O que a memória individual grava, recalca, exclui, relembra, é evidentemente o resultado de um verdadeiro trabalho de organização.

Pollak (1992) estabelece três elementos constitutivos da memória, individual ou coletiva: em primeiro lugar estão os acontecimentos vividos pessoalmente; em segundo lugar, são os acontecimentos que o autor denomina como "vividos por tabela" acontecimentos dos quais a pessoa não participou diretamente, mas que foram vividos pela coletividade à qual a pertence; e, em terceiro, a memória também é constituída por pessoas e personagens e lugares (ligados a uma lembrança que pode ser pessoal ou "herdada" da comunidade). De acordo com Selva Guimarães Fonseca,

[...] o registro da vida dos professores [e de suas memórias], de suas maneiras de ser e ensinar, situa-se neste campo movediço em que se cruzam os modos de ser do indivíduo e o mundo social, as instituições e os diferentes atores, grupos e conflitos sociais que fazem parte de suas trajetórias (2006, p. 35).

Tomando como referência o pesquisador Ivor F. Goodson (1992), a historiadora argumenta que as vidas dos professores e suas memórias,

podem ajudar-nos a ver o indivíduo em relação com a história de seu tempo, permitido-nos encarar a intersecção da história da vida com a história da sociedade, esclarecendo, assim, escolhas, contingências e opções com que se depara o indivíduo ... Isso reconceptualizaria os nossos estudos sobre escolaridade e currículo (GOODSON apud FONSECA, 2006, p. 31).

Temos como um dos objetivos na pesquisa, que ora desenvolvemos, analisar as memórias dos professores da Faculdade de Formação de Professores (FFP) de São Gonçalo, instituição, atualmente vinculada a Universidade do Estado do Rio de Janeiro, acerca da trajetória da licenciatura curta em estudos sociais, oferecida nesta instituição, entre os anos 1970 e $1980^{14}$. Entretanto, ao realizarmos as primeiras entrevistas com os docentes, vislumbramos muitas outras questões que ajudam a compreender muito além das trajetórias pessoais de vida ou o período em que estas pessoas lecionaram na FFP. Estes docentes narram aspectos da trajetória da educação brasileira nos últimos trinta anos e as 
formas como vivenciaram este período. Destacamos alguns trechos da entrevista realizada com a professora Dalva das Graças Fernandes de $\mathrm{Sa}^{15}$ sobre sua formação em filosofia, aspectos de sua inserção na FFP e aspectos de sua trajetória enquanto professora em diferentes segmentos de ensino.

Fiz PUC [Pontifícia Universidade Católica do Rio de Janeiro], eu fiz vestibular para Filosofia e foi uma época que não foi uma época fácil, terminei Filosofia em 1974, entendeu, estudei num período de recessão muito grande [...] então não era assim um curso que você visse tudo, que os professores falassem claramente sobre tudo, não era. Alguns professores mais próximos dos alunos muitas vezes davam aula fora da sala de aula. Nós éramos poucos alunos, oito alunos para fazer História da Filosofia I, II, para fazer Filosofia da Ciência, seis, sete, não tinha muito mais que isso em sala não [...] os que vinham de fora, eram de outros cursos, que as vezes se interessavam pela matéria e faziam, mas normalmente o curso de Filosofia não tinha mais do que oito ou nove alunos em sala.

Não me vejo fazendo outra coisa, eu queria ser professora, profissão minha mesmo, escolha minha, não foi escolha de mãe ou de pai, nada disso. Eu queria ser professora mesmo [...] amigas minhas na época estudaram outros cursos, fizeram Psicologia, amigas que foram para Direito, mas eu queria mesmo é ser professora...

Eu acho que tive uma formação muito boa, não foi melhor, por que, como eu disse para você anteriormente, nós não tínhamos um curso aberto, que todo mundo pudesse falar tudo, contar tudo, a história do Brasil como deveria ser contada. Não se falava muito em Filosofia, poucos cursos, poucas Universidades tinham filosofia, a Santa Ursúla fechou o curso na época em que eu entrei [...] só UFRJ e PUC na realidade tinham Filosofia, e quando eu entrei, tive que preencher uma documentação enorme [descrevendo] por que eu queria fazer aquele curso, quem eram meus pais, o quê que eu lia, o quê que eu não lia....

Na realidade, fiz minha vida profissional dentro de sala de aula como professora de Filosofia, que foi a melhor [opção] e na ocasião eu, eu tinha prestado concurso para mestrado [pouco tempo após a formação inicial], mas aí tínhamos que começar a trabalhar e eu comecei a trabalhar como horista lá na Faculdade [de Formação de Professores], eu fui levada pelo Emílio [professor que já atuava na instituição] como eu falei com você [...] então tinha muita carga horária, a carga horária era enorme...

Sobre sua prática docente e concepções de ensino a entrevistada nos apresenta questões importantes. 
[os alunos, futuros professores] Tinham que ter uma visão mais ampla mesmo [...] esta questão da fragmentação do ensino eu acho muito prejudicial, não sei se é por que a minha formação é filosofia que é uma coisa muito ampla. Quando se estuda filosofia a gente vê lá, Pitágoras com a matemática, Tales com a questão da Geografia, da Geometria, Descartes, no século XVII na França, estudando latim, literatura, matemática, então eu tenho esta visão, eu acho que isso é importante e acho que a gente não deve ficar fechada dentro de si...

Trabalhei um pouquinho só com Ensino Fundamental, a base mesmo é Ensino Médio. E eu acho que isso foi muito importante para eu entender o que a universidade precisa para formar o professor que irá trabalhar com o Ensino Básico, sabe? Isso é fundamental, ninguém podia ir direto para o Ensino Superior para trabalhar na Licenciatura sem ter uma vivência na escola de ensino fundamental e de ensino médio. Eu acho! Para você sentir como é o aluno, saber o que ele precisa [...].

A riqueza dos depoimentos permite pensar uma história da educação brasileira nos últimos anos a partir do que dizem os professores e pessoas que vivenciaram esta educação e as formas como ela se processou. Aspectos como a formação de professores de filosofia durante o Regime Civil-Militar que governou o Brasil entre 1964 e 1985, interdisciplinaridade e relação entre os diferentes segmentos do ensino fazem parte das memórias construídas pela professora na perspectiva apresentada por Gusmão (2004, p. 31): "lembrar é refazer, reconstruir, repensar, com idéias e imagens de hoje, as experiências do passado". Neste sentido, "estes testemunhos são fundamentais para conferir nitidez e consistência às realidades educativas que eles descrevem e explicam, funcionando de forma complementar face a outras fontes de informação, relativas a estas mesmas realidades" (MOGARRO, 2005, p. 14).

O registro das memórias dos professores permite compreender como estes sujeitos reconstroem suas experiências passadas (FONSECA, 2006, p. 34). Assim,

As investigações pedagógicas, que até pouco tempo insistiam em estudar a educação, a escola e o ensino, ignorando o professor, hoje tentam colocá-lo no centro dos debates. Isso decorre de uma questão óbvia: não há educação ou ensino sem professor, e o professor é uma pessoa (FONSECA, 2006, p. 43).

Tomando como fonte as memórias dos professores, deslocamos o enfoque, ainda tradicional entre os pesquisadores em história da educação, concedido às fontes escritas. Apresentamos uma possibilidade de pesquisa a partir dos relatos dos docentes e das formas como estes representam suas experiências enquanto pessoas que atuaram ou ainda atuam na educação brasileira. Trata-se de uma história em construção.

\section{Considerações Finais}

Tendo em vista a amplitude das temáticas abordadas ao longo do artigo, o quadro que traçamos, sem dúvida, não dá conta das diferentes concepções e métodos de pesquisa 
em história da educação e nem foi essa nossa intenção. Realizamos um estudo exploratório. Mais do que respostas, temos questões e são essas que movem o pesquisador. A busca de um lugar, de um referencial teórico-metodológico caracteriza a escrita deste texto. Podem os historiadores pesquisar a Educação e o seu desenvolvimento? A resposta é positiva. A partir de breves apontamentos sobre a pesquisa em história da educação no Brasil, observamos que, se esta surgiu ligada ao desenvolvimento dos cursos de formação de professores e a partir de uma concepção positivista da história, hoje, mais que nunca, a Educação torna-se objeto do historiador, independente do lugar em que seja "alocada", se como uma especialidade da História ou como uma subárea da Educação.

Uma nova forma de encarar história da educação vem caracterizando as pesquisas na área desde meados dos anos 1980. Nas palavras de Carvalho et alii (2008), um "movimento de reconfiguração da historiografia educacional" a partir da incorporação de novos temas, questões, procedimentos de pesquisa e perspectivas de abordagem. Um "movimento de renovação teórica, temática e metodológica". Neste percurso, temas tradicionais estão sendo revistos e outros, como as memórias dos professores ganham relevo.

Assim, num campo, onde ainda prevalece à fonte escrita, apresenta-se como possibilidade a história oral e as memórias de professores como uma fonte a mais para se analisar a história da educação brasileira. Definida a concepção de memória, destacamos pequenos trechos de entrevista realizada recentemente com uma professora que atuou no Ensino Superior, lecionando em cursos de Estudos Sociais, História e Geografia, e no Ensino Básico, lecionando Filosofia. Para além do que diz as legislações ou currículos, e tantas outras fontes escritas, destacam-se a subjetividade dos professores e as formas como constroem suas representações acerca da sua atividade e das formas como se processam a Educação.

Um caminho possível.

\section{Referências}

BLOCH, Marc. Apologia da História. Rio de Janeiro: Jorge Zahar Editor, 2001.

BRANDÃO, Carlos Rodrigues. O que é educação? 33ª ed. São Paulo: Brasiliense, 1995.

CARDOSO, Ciro Flamarion; VAINFAS, Ronaldo (Orgs.). Domínios da história: ensaios de teoria e metodologia. Rio de Janeiro: Campus, 1997.

CARVALHO, Marta Maria Chagas de; SAVIANI, Dermeval; VIDAL, Diana. Sociedade Brasileira de História da Educação: constituição, organização e realizações. São Paulo, jul./2006. Disponível em: < http://www.sbhe.org.br/historico > Acesso em: 28/12/2010.

CATANI, Denise Bárbara; FARIA FILHO, Luciano Mendes de. Um lugar de produção e a produção de um lugar: a história e a historiografia divulgadas no GT História da Educação da ANPEd (1985 - 2000). Revista Brasileira de Educação, Rio de Janeiro, n. 19, p. 113 128, Jan/Fev/Mar/Abr. 2002.

CATROGA, Fernando. Memória, História e Historiografia. Coimbra: Quarteto, 2001.

CIAMPI, Helenice. O professor de História e a produção dos saberes escolares: O Lugar da Memória. In: FERREIRA, Antonio C; BEZERRA, Holien G; LUCCA, Tânia Regina de (Orgs.). O Historiador e o seu tempo. São Paulo: Editora UNESP, 2008. p. 203 -221.

DELGADO, Lucilia de Almeida Neves. História Oral, memória, identidades. Belo Horizonte: Autêntica, 2006. p. $15-66$. 
FALCON, Francisco. História cultural e história da educação. Revista Brasileira de Educação, Rio de Janeiro, v. 11, n. 32, p. 328 - 339, maio/ago. 2006.

FELGUEIRAS, Margarida Louro. Pensar a história, repensar o seu ensino. A disciplina de história no $3^{\circ}$ ciclo do Ensino Básico: Alguns princípios orientadores da metodologia de ensino. Porto: Porto Editora, 1994. p. 25 - 69.

FENELON, Déa. A questão de Estudos Sociais. In: ZAMBONI, Ernesta. A prática do ensino de história. São Paulo: Vozes/Cedes, 1984. p. 11 - 22.

FERREIRA, Jorge; DELGADO, Lucilia (Orgs.). O Brasil Republicano. Rio de Janeiro: Civilização Brasileira, 2003. 4 volumes.

FERREIRA, Marieta de Moraes. Desafios e dilemas da história oral nos anos 90: o caso do Brasil. História Oral, São Paulo, n. 1, p. 19 - 30, 1998.

FICO, CARLOS; ARAÚJO, Maria Paula (Orgs.). 1964 - 2004: 40 anos do golpe: ditadura militar e resistência no Brasil. Rio de Janeiro: 7Letras, 2004.

FONSECA, Selva Guimarães. O ensino de História e o golpe militar de 1964. In: FICO, CARLOS; ARAÚJO, Maria Paula (Orgs.). 1964 - 2004: 40 anos do golpe: ditadura militar e resistência no Brasil. Rio de Janeiro: 7Letras, 2004. p. 364 - 377.

FONSECA, Selva Guimarães. Ser professor no Brasil: história oral de vida. $3^{\mathrm{a}}$ ed. Campinas/SP: Papirus, 2006.

FONSECA, Thais N. de L História da Educação e História Cultural. In: FONSECA, Thais N. de L; VEIGA, Cynthia Greive (Orgs.). História e Historiografia da Educação no Brasil. Belo Horizonte: Autêntica, 2003.

FONSECA, Thais N. de L; VEIGA, Cynthia Greive (Orgs.). História e Historiografia da Educação no Brasil. Belo Horizonte: Autêntica, 2003.

GASPARELLO, Arllete. Encontros de saberes: as disciplinas escolares, o historiador da educação e o professor. In: MONTEIRO, Ana Maria; GASPARELLO, Arllete;

MAGALHÃES, Marcelo (Orgs.). Ensino de História: sujeitos, saberes e práticas. Rio de Janeiro: Mauad X/FAPERJ, 2007. p. 73 - 89.

GERMANO, José Willington. Estado Militar e Educação no Brasil (1964 - 1985). $2^{\mathrm{a}}$ ed. São Paulo: Cortez, 1995.

GONDRA, José Gonçalves (Org.). Pesquisa em história da educação no Brasil. Rio de Janeiro: DP\&A Editora, 2005.

GOODSON, Ivor F. Dar voz ao professor: as histórias de vida do professor e seu desenvolvimento profissional. In: NÓVOA, A (Org.). Vidas de Professores. Porto: Porto Editora, 1992. p. 51 - 77.

GUSMÃO, Emery Marques. Memórias de quem ensina História: Cultura e Identidade Docente. São Paulo: UNESP, 2004.

HALBWACHS, Maurice. A memória coletiva. $1^{\text {a }}$ ed. $3^{\text {a }}$ reimpressão. São Paulo: Centauro, 2006.

KOSELLECK, Reinhart. Futuro passado: contribuição à semântica dos tempos históricos. Rio de Janeiro: Contraponto/Ed. PUC-Rio, 2006. p. 21 - 60.

LE GOFF, Jacques. Prefácio. In: BLOCH, Marc. Apologia da História. Rio de Janeiro: Jorge Zahar Editor, 2001. p. 15 - 34. 
. História e Memória. 5ª ed. Campinas/SP: Editora da UNICAMP, 2003.

LOPES, Eliane Marta Teixeira. História da educação ou educação pela história? Educação em Revista, Belo Horizonte, n. 1, p. 8 - 12, 1985.

MESQUITA, Ilka Miglio de; FONSECA, Selva. Formação de Professores de História: experiências, olhares e possibilidades. Revista de História Unisinos, Minas Gerais, v. 10, n. 3, p. 333 - 343, setembro/dezembro 2006.

MOGARRO, Maria João. Memórias de professores: Discursos orais sobre a formação e a profissão. História da Educação, Pelotas, n. 17, p. 7 - 31, Abril/2005.

NADAI, Elza. O ensino de História no Brasil: trajetória e perspectiva. Revista Brasileira de História, São Paulo, v. 13, n 25/26, p. 143 - 165, set. 1992/ago. 1993.

NASCIMENTO, Maria Isabel; NASCIMENTO, Manoel Nelito Matheus. O lugar da história na formação do professor, Revista HISTEDBR Online, Campinas/SP, n. 38, p. 186 - 196, Jun./2010.

NASCIMENTO, Thiago Rodrigues. Memórias de quem ensina História: reflexões acerca da formação de professores e a prática docente. In: AYRES, Ana Cléa; GUIMARÃES, Gláucia; MENDES, Regina; DIAS, Rosimeri (Orgs.). Articulando a Universidade e a Escola Básica no Leste Fluminense. Rio de Janeiro: H. P. Comunicação Editora, 2010. p. $17-24$.

NUNES, Clarice. As políticas educacionais pós-64 e o conflito de representações de uma educação voltada para o trabalho. In: FICO, CARLOS; ARAÚJO, Maria Paula (Orgs.). 1964 - 2004: 40 anos do golpe: ditadura militar e resistência no Brasil. Rio de Janeiro: 7Letras, 2004. p. $351-363$.

PESAVENTO, Sandra Jatahy. História \& História Cultural. $2^{\mathrm{a}}$ ed. Belo Horizonte: Autêntica, 2008.

POLLAK, Michael. Memória e Identidade Social. Estudos Históricos, Rio de Janeiro, vol. 5, n. 10, p. $200-212,1992$.

REIS FILHO, Daniel Aarão; FERREIRA, Jorge; ZENHA, Celeste (Orgs.). O século XX. Rio de Janeiro: Civilização Brasileira, 2000. 3 volumes.

REIS FILHO, Daniel Aarão; RIDENTI, Marcelo; MOTTA, Rodrigo (Orgs.). O golpe e a ditadura militar: 40 anos depois (1964 - 2004). Bauru/SP: EDUSC, 2004.

REZNIK, Luís. A construção da memória no ensino da História. In: FICO, CARLOS; ARAÚJO, Maria Paula (Orgs.). 1964 - 2004: 40 anos do golpe: ditadura militar e resistência no Brasil. Rio de Janeiro: 7Letras, 2004. p. 339 - 350.

ROMANELLI, Otaíza de Oliveira. História da Educação no Brasil (1930/1973). 32a edição. Petrópolis: Vozes, 2007.

ROUSSO, Henry. A memória não é mais o que era. In: FERREIRA, Marieta de Morais; AMADO, Janaína (Orgs.). Usos \& Abusos da História Oral. $5^{\text {a }}$ ed. Rio de Janeiro: Ed. FGV, 2002. p. 93 - 101.

SARLO, Beatriz. Tempo Passado: cultura da memória e guinada subjetiva. São Paulo: Companhia das Letras, 2007. 


\section{SILVEIRA, João Batista da. A política de formação de professores de história no Regime Civil-Militar: A criação da Licenciatura Curta em Estudos Sociais. 2008. $159 \mathrm{f}$. Dissertação (Mestrado em Educação) - Faculdade de Educação, PUC/Campinas, 2008. SOCIEDADE BRASILEIRA DE HISTÓRIA DA EDUCAÇÃO (Org.). Educação no Brasil: História e Historiografia. Campinas/SP: Autores Associados, 2001.}

THOMPSON, Paul. História e Comunidade. In: A Voz do Passado. $2^{\mathrm{a}}$ ed. Rio de Janeiro: Paz e Terra, 1992. p. 20 - 40.

VIDAL, Diana Gonçalves; FARIA FILHO, Luciano Mendes de. História da educação no Brasil: a constituição histórica do campo (1880 - 1970). Revista Brasileira de História, São Paulo, v. 23, n. 45, p. 37 - 70, 2003.

WARDE, Mirian Jorge. Contribuições da história para a educação. Em Aberto, Brasília, ano 9, n. 47, p. 3 - 11, Jul./Set. 1990.

\section{Notas}

${ }^{1}$ Agradeço a Thiago de Souza Junior pela leitura deste trabalho desde os primeiros momentos. A Gelson Gomes pelas muitas discussões historiográficas processadas ao longo do último ano. A História da Educação continua sendo um desafio. Aos amigos que fiz no PPGHS/UERJ.

${ }^{2}$ Mestrando no Programa de Pós-Graduação em História Social da Faculdade de Formação de Professores (FFP) da Universidade do Estado do Rio de Janeiro (PPGHS/UERJ). Bolsista da Fundação de Amparo à Pesquisa do Estado do Rio de Janeiro (FAPERJ). Contato: thiagorodrigues.uerj@ yahoo.com.br.

${ }^{3}$ Em 1964 um golpe civil-militar derrubou o presidente João Goulart e iniciou-se o que seria a mais longa ditadura brasileira. Após o golpe de 1964, se processaram importantes modificações na política educacional brasileira, que podem ser observadas nas Reformas do Ensino Universitário (Lei 5.540/68) e do Ensino de $1^{\circ}$ e $2^{\circ}$ graus (Lei 5.692/71). Segundo Elza Nadai (1993) "modificações legais impuseram ainda profundas transformações no projeto de formação de professores que vinha sendo realizado, tornando-o de 'curta duração', pobre em conteúdo cientifico, aligeirado e polivalente”. Negou-se à História o seu caráter autônomo a partir da inclusão dos Estudos Sociais, componente curricular que integrava a História e a Geografia no currículo do Ensino Fundamental, e diminuiu a carga horária da disciplina no Ensino Médio. Sob a alegação de que havia uma demanda educacional pela formação do professor polivalente, proliferou cursos de licenciatura curta em diferentes regiões do Brasil. É o caso do curso de Licenciatura curta em Estudos Sociais da Faculdade de Formação de Professores (FFP) que iniciou suas atividades em 1973.

${ }^{4}$ Sobre história da educação brasileira durante o regime republicano podemos citar clássicos como os livros de Otaíza de Oliveira Romanelli (2007) e José Willington Germano (1995) e trabalhos recentes como a dissertação de João Batista da Silveira (2008) sobre A política de formação de professores de história no Regime Civil-Militar. No mesmo ano de publicação do livro de Daniel Aarão Reis Filho et alii., foi lançado um outro livro com a mesma temática, os 40 anos do golpe civil-militar, que merece destaque. $1964-2004$ 40 anos do golpe: ditadura militar e resistência no Brasil, organizado por Carlos Fico e Maria Paula de Araújo (2004), originário do seminário realizado em março de 2004 no IFCS/UFRJ, ICHF/UFF e na FGV dedica três capítulos ao Ensino, escritos por Clarice Nunes, Luís Reznik e Selva Fonseca Guimarães, pesquisadores de reconhecida trajetória no campo do Ensino de História e História da Educação.

${ }^{5}$ Ver, dentre outros, Veiga e Fonseca (Orgs.), 2003; Sociedade Brasileira de História da Educação (Org.), 2001; Vidal e Faria Filho (2003); Gondra (2005).

${ }^{6}$ Neste trecho, o historiador Jacques Le Goff, ao prefaciar o livro Apologia da História de Marc Bloch, sintetiza a concepção de História apresentada por Bloch.

${ }^{7}$ Destes 15 volumes: três dedicados a Instrução e ao Império, publicados entre 1936 e 1938; três sobre a Instrução e as Províncias (entre 1939 e 1940); sete dedicados a Instrução e a República, publicados entre 1941 e 1942, dois dedicados a Instrução Pública no Estado de São Paulo e um a Instrução primaria e secundária no município da Corte, os três lançados em 1942 (VIDAL e FARIA FILHO, 2003, p. 43). 
${ }^{8}$ Sob a liderança de Laerte Ramos de Carvalho, catedrático de História e Filosofia da Educação da Faculdade de Filosofia, Ciências e Letras da USP, um grupo de pesquisadores paulistas realizaram, a partir de pesquisa de campo, um levantamento da produção bibliográfica e da documentação referente à educação brasileira em arquivos e bibliotecas que posteriormente foram publicados (VIDAL e FARIA FILHO, 2003, p. 54 -55).

${ }^{9}$ Neste percurso, em 1999 foi criada a Sociedade Brasileira de História da Educação (SBHE) e, em 2001, a Revista Brasileira de História da Educação.

${ }^{10}$ Como exemplo de pesquisadores que iniciaram suas trajetórias de pesquisa nos cursos de graduação em história e depois direcionaram suas pesquisas para o campo da história da educação, podemos citar Diana Vidal, professora da Universidade de São Paulo, Arlette Medeiros Gasparello, professora do Programa de Pós-Graduação em Educação da Universidade Federal Fluminense (UFF) e Alessandra Frota Martinez de Schueler, que atualmente leciona na Faculdade de Educação da UFF e coordena um projeto sobre a expansão da escola primária no Rio de Janeiro (1850 - 1946).

${ }^{11}$ A partir dos anos 1980 e, sobretudo, anos 1990 e 2000, as pesquisas em educação, história da educação e mesmo ensino de história têm deixado de ser processadas, exclusivamente, no âmbito das Faculdades e Programas de Pós em Educação. Uma pesquisa sobre esta produção acadêmica em história da educação no âmbito dos Programas de Pós-Graduação em História ainda está por ser feita.

${ }^{12}$ Sandra Jatahy Pesamento (2008, p. 7 - 8), em seu livro História \& História Cultural, argumenta "que a História Cultural corresponde, hoje, cerca de $80 \%$ da produção historiográfica nacional, expressa não só nas publicações especializadas, sob forma de livros e artigos científicos, como nas apresentações de trabalhos, em congressos e simpósios, ou ainda nas dissertações e teses, defendidas e em andamento, nas universidades brasileiras". Um corrente da historiografia educacional argumenta que a história da educação situa-se como um dos campos de investigação da História Cultural (FONSECA, 2003).

${ }^{13}$ Adaptado de Nascimento (Thiago), 2010, p. 17.

${ }^{14}$ Como a História Oral pressupõe a equiparação do uso da documentação oral ao uso de fontes escritas, para além das memórias dos professores, analisamos os Pareceres do Conselho Estadual de Educação do Rio de Janeiro que autorizaram o funcionamento dos cursos da FFP e, posteriormente, trataram das alterações curriculares que a Licenciatura Curta em Estudos Sociais sofreu ao longo dos anos setenta e oitenta. Os currículos desta Licenciatura na FFP, bem como as ementas das disciplinas oferecidas, produzidas entre 1973-1986. E as Atas das Reuniões que ainda estão disponíveis na Faculdade, são elas: Atas do Conselho Departamental (1973-1987); Atas do Departamento de Estudos Sociais (1973-1987) e Atas do Departamento de Educação (1974-1987). Os currículos, ementas e Atas encontram-se sob guarda, da Secretaria da FFP, do Laboratório de Ensino de História da Faculdade de Formação de Professores da UERJ e do Acervo organizado pelo Projeto, A Faculdade de Formação de Professores em São Gonçalo: movimentos de uma história em construção (1971 - 1987), liderado pela professora Ana Cléa Ayres.

15 Entrevista realizada com a professora Dalva das Graças Fernandes de Sá, em sua residência, no dia 12/11/2010. A professora autorizou a transcrição e a utilização de sua entrevista para fins acadêmicos. Formada em Filosofia, Dalva Sá lecionou por mais de duas décadas na Faculdade de Formação de Professores nas licenciaturas curta em Estudos Sociais, Plena em História, Plena em Geografia. Aposentada no Ensino Superior, ainda leciona em escolas estaduais do Rio de Janeiro.

Recebido em: $\quad$ 27/01/11

Aprovado em: $17 / 07 / 11$ 